\title{
Extracellular Vesicle microRNAs Contribute to the Osteogenic Inhibition of Mesenchymal Stem Cells in Multiple Myeloma
}

\author{
Stefania Raimondo ${ }^{1}$, Ornella Urzì ${ }^{1}$, Alice Conigliaro ${ }^{1} \mathbb{D}$, Giosuè Lo Bosco ${ }^{2,3}$, Sofia Parisi ${ }^{1}$, \\ Melania Carlisi ${ }^{4}$, Sergio Siragusa ${ }^{4}$, Lavinia Raimondi ${ }^{5}$ (D), Angela De Luca ${ }^{5}$, \\ Gianluca Giavaresi ${ }^{5}$ (D) and Riccardo Alessandro ${ }^{1, *(D)}$ \\ 1 Department of Biomedicine, Neuroscience and Advanced Diagnostics (Bi.N.D.), Section of Biology and \\ Genetics, University of Palermo, 90133 Palermo, Italy; stefania.raimondo@unipa.it (S.R.); \\ ornella.urzi@gmail.com (O.U.); alice.conigliaro@unipa.it (A.C.); sofia.parisi91@gmail.com (S.P.) \\ Department of Mathematics and Computer Science, University of Palermo, 90133 Palermo, Italy; \\ giosue.lobosco@unipa.it \\ 3 Department of Sciences for technological innovation, Euro-Mediterranean Institute of Science and \\ Technology, 90133 Palermo, Italy \\ 4 Department of Health Promotion, Mother and Child Care, Internal Medicine and Medical \\ Specialties (ProMISE), Haematology Unit, University of Palermo, 90133 Palermo, Italy; \\ melania.carlisi@unipa.it (M.C.); sergio.siragusa@unipa.it (S.S.) \\ 5 IRCCS Istituto Ortopedico Rizzoli, 40136 Bologna, Italy; lavinia.raimondi@ior.it (L.R.); \\ angela.deluca@ior.it (A.D.L.); gianluca.giavaresi@ior.it (G.G.) \\ * Correspondence: riccardo.alessandro@unipa.it
}

Received: 13 January 2020; Accepted: 10 February 2020; Published: 14 February 2020

\begin{abstract}
Osteolytic bone disease is the major complication associated with the progression of multiple myeloma (MM). Recently, extracellular vesicles (EVs) have emerged as mediators of MM-associated bone disease by inhibiting the osteogenic differentiation of human mesenchymal stem cells (hMSCs). Here, we investigated a correlation between the EV-mediated osteogenic inhibition and MM vesicle content, focusing on miRNAs. By the use of a MicroRNA Card, we identified a pool of miRNAs, highly expressed in EVs, from MM cell line (MM1.S EVs), expression of which was confirmed in EVs from bone marrow (BM) plasma of patients affected by smoldering myeloma (SMM) and MM. Notably, we found that miR-129-5p, which targets different osteoblast (OBs) differentiation markers, is enriched in MM-EVs compared to SMM-EVs, thus suggesting a selective packaging correlated with pathological grade. We found that miR-129-5p can be transported to hMSCs by MM-EVs and, by the use of miRNA mimics, we investigated its role in recipient cells. Our data demonstrated that the increase of miR-129-5p levels in hMSCs under osteoblastic differentiation stimuli inhibited the expression of the transcription factor Sp1, previously described as a positive modulator of osteoblastic differentiation, and of its target the Alkaline phosphatase (ALPL), thus identifying miR-129-5p among the players of vesicle-mediated bone disease.
\end{abstract}

Keywords: extracellular vesicles (EVs); exosomes; multiple myeloma (MM); bone disease; microRNAs; osteogenic differentiation; transcription factor sp1

\section{Introduction}

Multiple myeloma (MM) represents the second most prevalent hematologic malignancy [1], is classified in a heterogeneous group of diseases, plasma cellular dyscrasias, characterized by the monoclonal expansion of bone marrow (BM) plasma cells that release a monoclonal immunoglobulin, 
called M component or paraprotein. The occurrence of MM is consistently preceded by two precursor states: a pre-cancerous condition called gammopathy of undetermined significance (MGUS) and the asymptomatic clonal plasma cell disorder called smoldering myeloma (SMM). SMM is distinguished from MGUS by a much higher risk of progression to MM [2].

The major complication, associated with MM disease progression, which is not observed in the other two conditions, is the bone disease. In fact, around $80 \%$ of patients develop osteolytic bone lesions that lead to fractures and bone pain [3]. The occurrence of osteolytic bone disease is the consequence of the alteration of the physiological balance between the activity of bone-resorbing osteoclasts (OCs) and bone-forming osteoblasts (OBs) that results in the concomitant activation of osteoclastogenesis and inhibition of osteoblastogenesis [4,5]. A better understanding of the underlying causes of bone disruption in patients affected by MM is needed to develop new targeted therapeutic strategies aimed at inhibiting osteolysis and stimulating $\mathrm{OB}$ differentiation. It has been extensively reported that $\mathrm{MM}$ cells are able to induce the remodeling of the bone marrow stromal tissue to promote their growth and survival. For this purpose, the bidirectional crosstalk between MM cells and Bone marrow stromal cells (BMSCs) is crucial [6].BMSC differentiation is regulated by a number of cytokines as well as miRNAs [7,8]. To note, several miRNAs can exhibit inhibitory roles in osteogenesis by directly or indirectly targeting key osteogenic factors [9]. In order to further investigate the multiple mechanisms adopted by MM cells to influence the tumor microenvironment, in the last years, we and other research groups have been working on understanding if MM-extracellular vesicles(EVs) can affect the balance between OC and OB functions.

EVs are a heterogeneous population of membrane-bound vesicles, released by almost all cell types, differing in sizes, secretory pathways, and content $[10,11]$. EVs have a sophisticated composition, including lipids, proteins, DNA, coding and non-coding RNA species, and, through different mechanisms, can interact with target cells, leading to phenotypic changes of recipient cells. For all these reasons, they are considered mediators of intercellular communication also in the tumor microenvironment. Numerous observations indicate that EVs play a crucial role in MM pathogenesis [12,13] by affecting endothelial cell functions [14-17], enhancing tumor cell proliferation [18], and promoting immunosuppression [14,19]. In addition, EVs that contain miRNAs may be an important means of cell-cell communication within the MM tumor microenvironment [20]. Recent studies have shown that MM cell-derived EVs play a relevant functional role in activating osteoclast differentiation [21-23] and that the presence of the EGFR ligand amphiregulin is partially responsible for OC activation [21]. Interestingly, increasing evidence reported that MM EVs are also effective in inhibiting osteogenesis, in particular by blocking the osteoblastic differentiation of mesenchymal cells [21,23-27]. In particular, the decrease in ALPL levels, both at the transcript and protein levels, was largely correlated with MM-EVs mediated osteogenic inhibition $[21,23,24]$. We have previously demonstrated that MM1.S-derived EVs led to a reduced expression of OB differentiation markers (ALPL, OCN, Col1A1) in hTERT-MSCs under osteogenic conditions [21]. Further observation showed that EVs from the syngenic murine model of MM blocked OBs differentiation and their functionality in vitro [23]. In particular, the authors found that EVs contain and transfer the inhibitor of Wnt/ $\beta$-catenin pathway, Dickkopf-1 (DKK1) [28], to OBs, leading to the reduction of the OB marker Runx2, Osterix, and Collagen 1A1 [23]. The EV-mediated decrease of Runx2 expression in hMSCs was also correlated to the transport of exosomal antisense lncRUNX2 from MM cells to recipient hMSCs [27].

Specificity Protein 1 (Sp1) is a key transcription factor involved in several biological pathways, acting as positive or negative gene expression regulator; in particular it plays a critical role in cell proliferation, cell cycle progression and apoptosis [29-31]. Emerging studies report a role of Sp1 in $\mathrm{OB}$ differentiation; in fact, its downregulation prevents vascular calcification by inhibiting the transdifferentiation of vascular smooth muscle cells into OBs [32]. In addition, Sp1 increases the mineralization of osteoblastic cells [33]. Modulation of Sp1 by EVs was recently correlated to their content; in particular Wang and colleagues reported that TGF- $\beta 1$ increases miR-135 levels in MSC-EVs. EVs containing miR-135 were able to promote chondrocyte proliferation by down-regulating Sp1 [34]. 
Although different mediators of the inhibitory effect of MM EVs have been already identified, the rich and heterogeneous content of EVs deserves further investigation in order to deeply investigate how MM cell-derivedEVs may act on osteoblast differentiation. In particular, this study aims to correlate the EV-mediated osteogenic inhibition of hMSCs with vesicle content, focusing on miRNAs.

\section{Results}

\subsection{EVs Are Internalized by hMSCs and Inhibit Their Osteogenic Differentiation}

EVs released by MM cells have been recently correlated to the MM bone disease by directly activating osteoclast functions and, at the same time, by inhibiting the osteogenic differentiation of hMSCs [21-25,27]. In our previous study, we demonstrated that MM EVs inhibit the osteoblastic differentiation of hTERT-MSCs [21]; here we tried to shed light on the mechanism underlying these effects. We first confirmed that EVs from MM1.S and RPMI 8226 cells were internalized by hMSCs (Figure 1A). Then, in order to investigate the effects induced by EVs in hMSCs during osteogenic differentiation, we analyzed the mRNA levels of the early osteogenic differentiation markers, i.e., Osterix, ALPL, Col1A1, and Osteocalcin (OCN), in hMSCs treated for 10 days with EVs from MM cell lines. As reported in Figure 1B, we found a significant and similar reduction of the early markers Osterix, ALPL and Col1A1, between EVs released from the two cell lines, a variable diminished level of Osteocalcin, but we didn't observe any change in the expression level of Osteopontin, a late osteogenic marker (data not shown). Taken together these results confirmed the role of MM-EVs in inhibiting the early commitment of hMSCs toward osteogenic differentiation. 
A

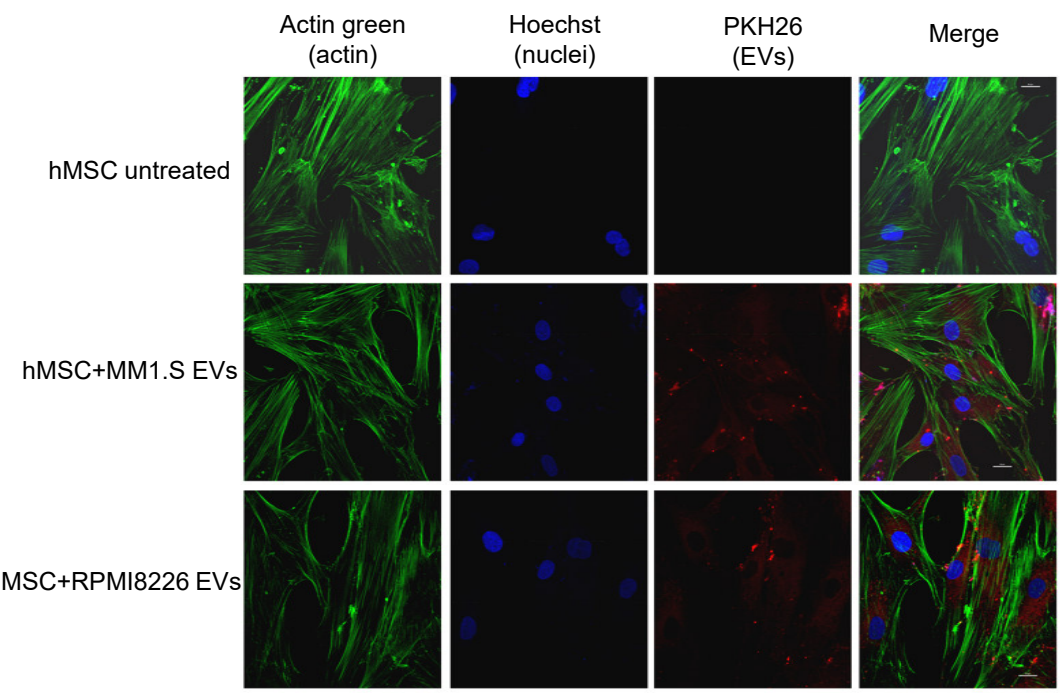

B

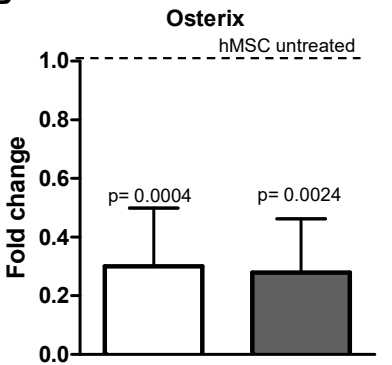

Col1a1
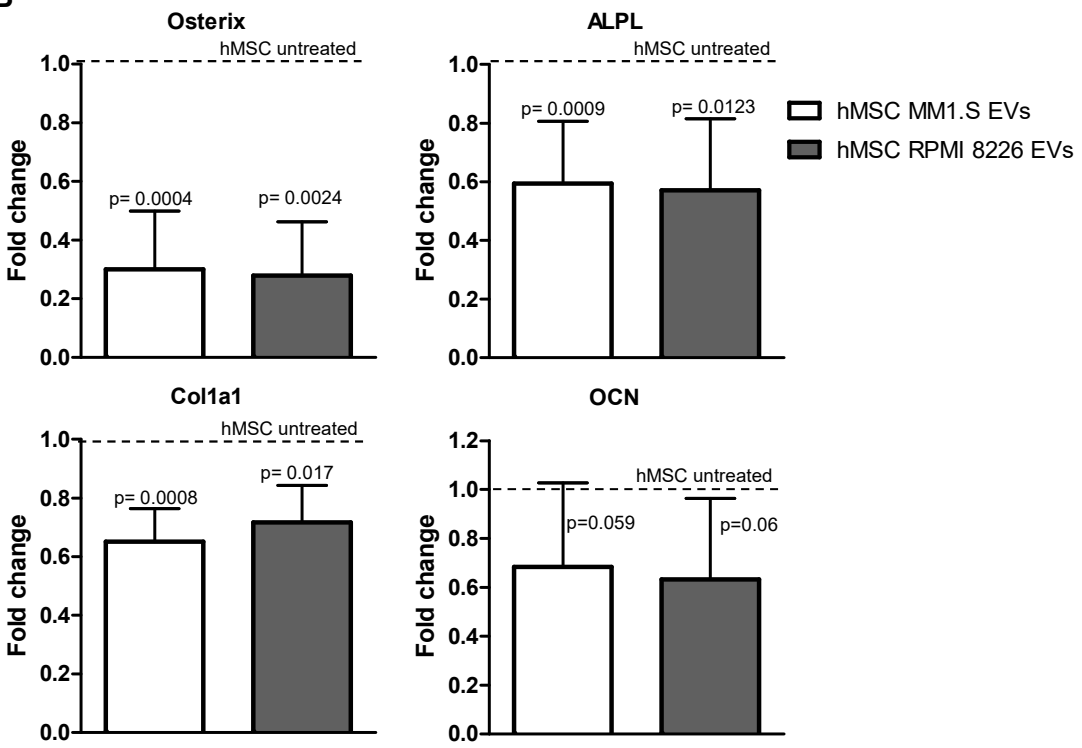

Figure 1. (A) Cellular internalization of MM1.S and RPMI 8226-derived EVs into hMSCs was analyzed by confocal microscopy. HMSCs were incubated for $4 \mathrm{~h}$ with MM-EVs labeled with PKH26 (red). HMSCs were stained with ActinGreen (green), nuclear counterstaining was performed using Hoescht (blue). Samples were analyzed at the confocal microscope (scale bar $=20 \mu \mathrm{m})$. (B) The Real-Time PCR analyses of Osterix, ALPL, Col1A1 and OCN were performed on hMSCs maintained in the osteogenic medium after 10 days of treatment with MM1.S and RMPI 8226-derived EVs. Data were normalized for $\beta$-actin and values are expressed as Fold Change in gene expression that occurred in cells treated with EVs versus untreated hMSCs (dotted line). The statistical significance of the differences was analyzed using a two-tailed Student's t-test.

\subsection{MM-EVs Contain miRNAs Involved in hMSCsOsteogenic Inhibition}

To investigate a possible correlation between the EV-mediated osteogenic inhibition of hMSCs and the miRNA vesicle content, we determined the miRNA expression profile of MM1.S EVs, using a quantitative TaqMan real-time PCR-based microRNA array card. Among the 384 microRNAs contained in the card, we identified 164 miRNAs in EVs from the MM1.S cell line and we then selected the most enriched ones based on their expression level ( $\mathrm{Ct}<31,2 \wedge \Delta \mathrm{Ct} \geq 0.002)$. Out of forty enriched miRNAs, seven of them have been previously correlated with osteogenesis regulation (hsa-miR-34a [35-37], hsa-miR-30c [26,38], hsa-miR-127-5p [39,40], hsa-miR-106a [41], hsa-miR-188-3p [37], hsa-miR-129-5p [42-45], hsa-miR-146a [46,47] (Figure 2)). 


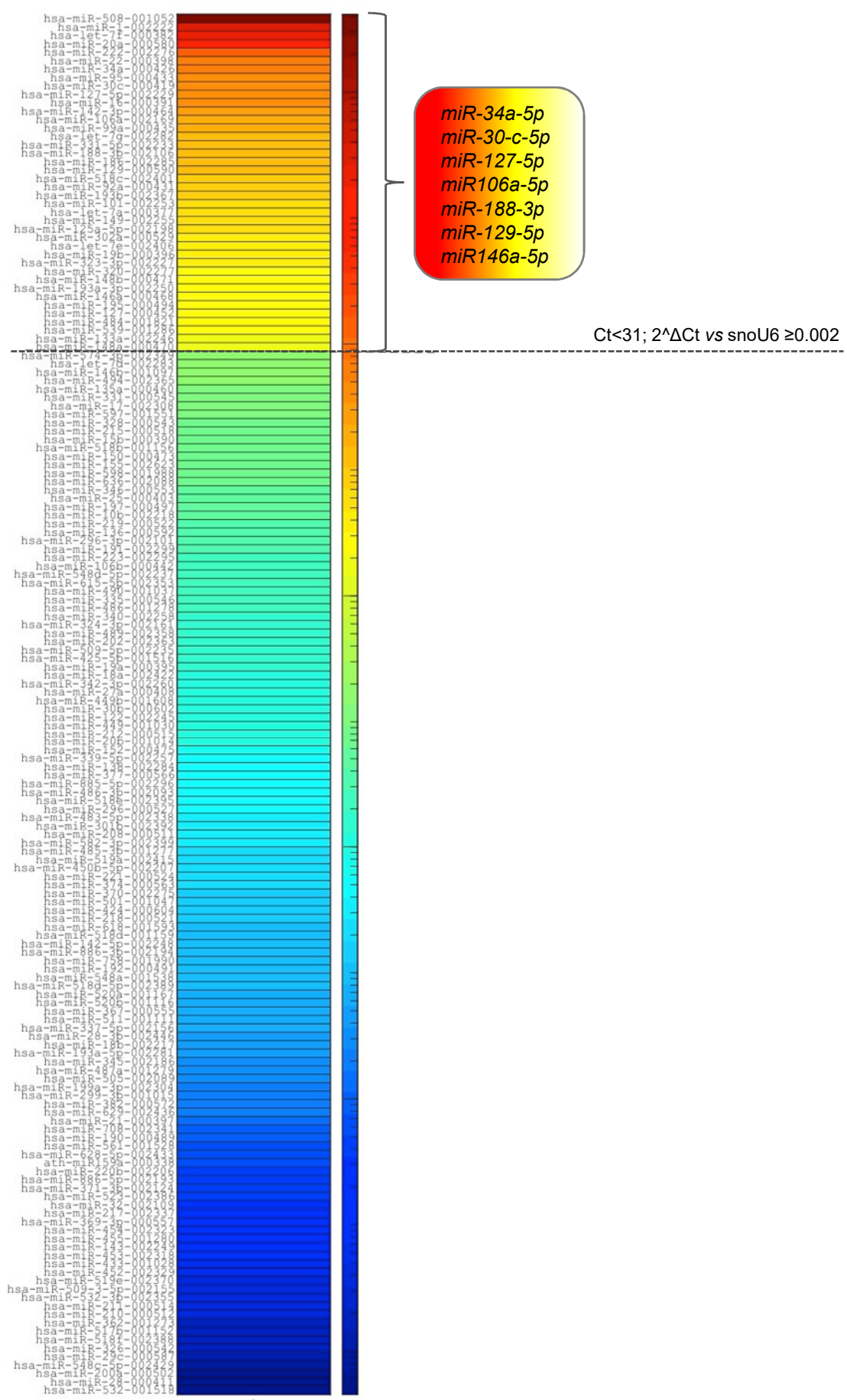

Figure 2. Heat map diagram of the miRNA profile of MM1.S-EVs based on miRNA expression ( $2^{\wedge} \Delta \mathrm{Ct}$ vs snoU6). The dotted line separates the miRNAs with higher abundance $\left(\mathrm{Ct}<31,2^{\wedge} \Delta \mathrm{Ct} \geq 0.002\right)$ from the less abundant species $(\mathrm{Ct}>31,2 \wedge \Delta \mathrm{Ct}<0.002)$.

Among those, we decided to focus our attention on hsa-miR-30c, hsa-miR-127-5p, hsa-miR-129-5p, and hsa-miR-146a since their validated and predicted targets are osteoblast differentiation markers. The presence of the four selected miRNAs in MM EVs was further confirmed by qRT-PCR in MM1.S and RPMI 8226 EVs as well as in the respective producing cell lines (Figure 3A). Although each of the four miRNAs is expressed in the two cell lines and is contained in their respective vesicles, we compared the abundance of each miRNA among the two MM cell lines and among the two EV population; to note we observed a comparable amount of miR-30c, miR-127-5p, and miR-129-5p in the two cell lines, 
while miR146a-5p is more abundant in MM1.S cells compared with RPMI8226. We performed the same analysis on EVs and we found that miR-30c is more abundant in RPMI8226-EVs compared with MM1.S-EVs, while the levels of the other miRNAs was comparable among the two vesicle types.

A
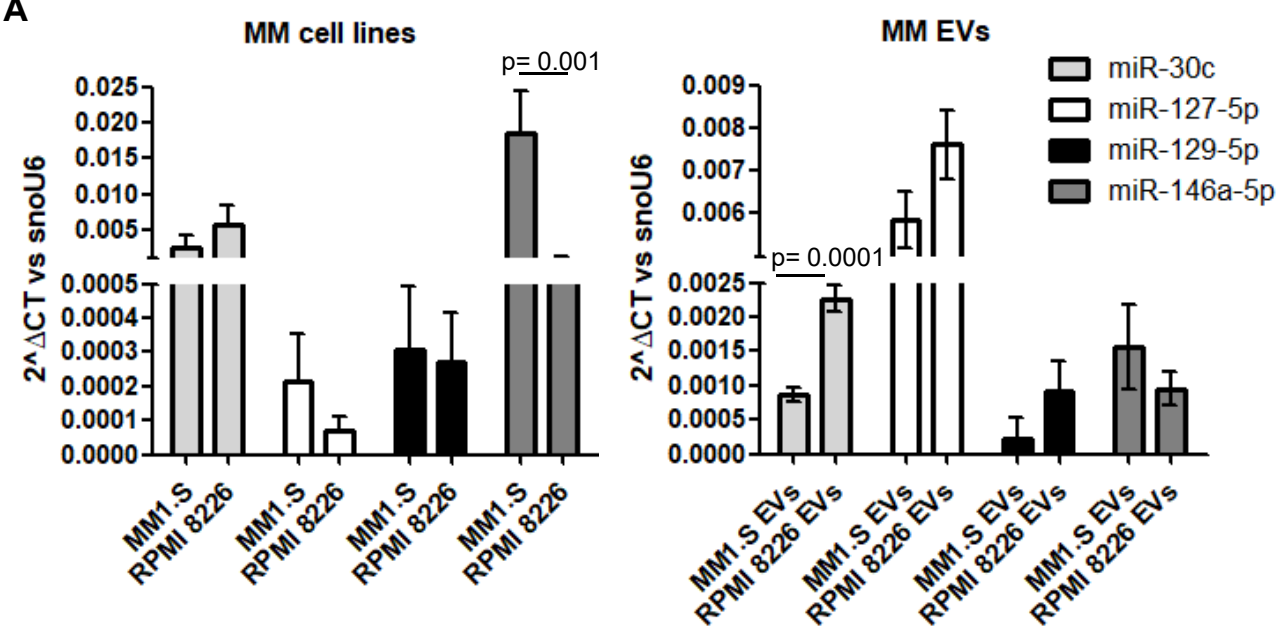

B
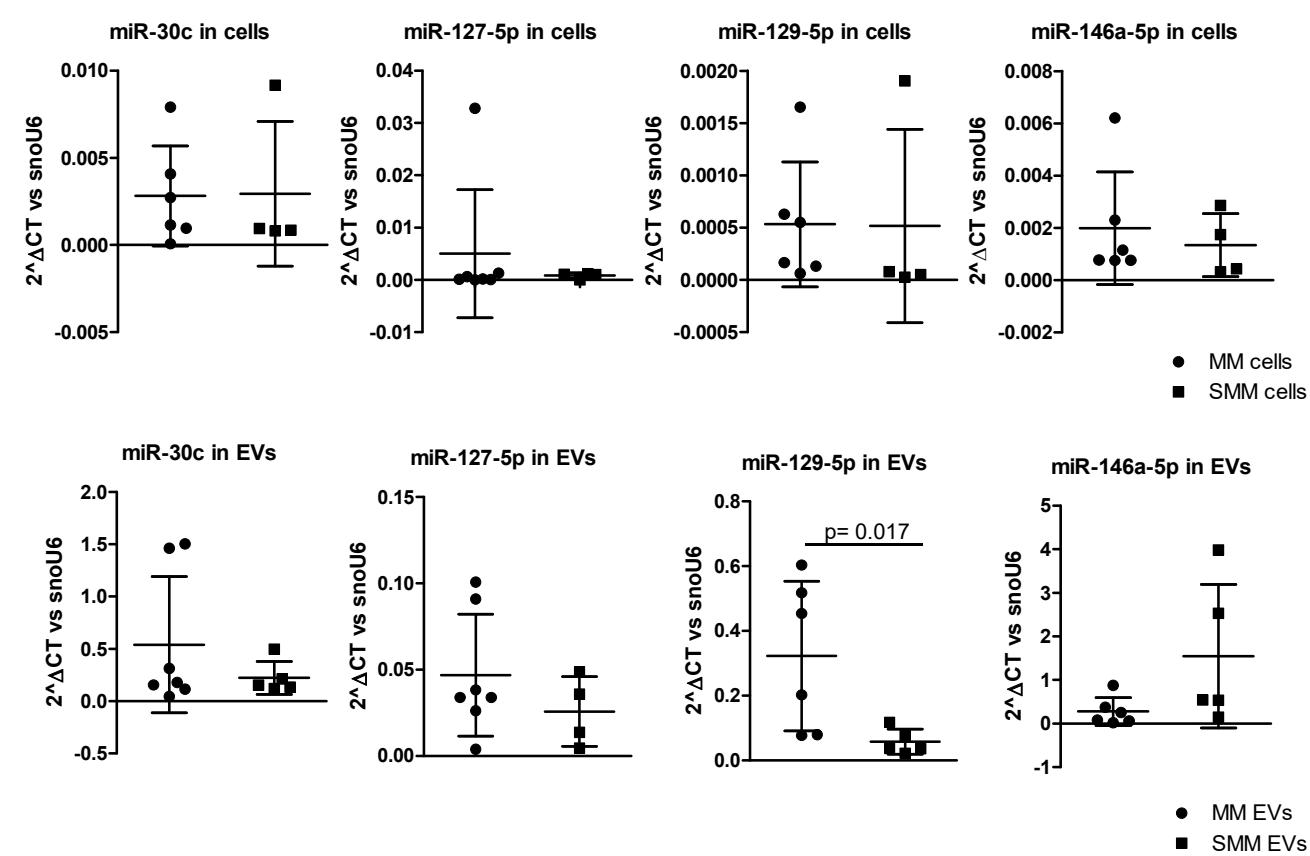

Figure 3. (A) Real-time PCR analyses for miR-30c, miR-127-5p, miR-129-5p and miR-146a-5p was performed on MM1.S and RPMI 8226 cells and EVs. The statistical significance of the differences was analyzed using a two-tailed Student's $t$-test. (B) Real-time PCR analysis for miR-30c, miR-127-5p, miR-129-5p and miR-146a-5p was performed on cells and EVs from the bone marrow aspirates of MM patients $(n=6$ to7) and SMM patients $(n=4$ to5). Values are plotted as $2 \wedge \Delta$ t versus snoU6. The statistical significance of the differences was analyzed using Mann-Whitney test.

Once we identified and selected specific microRNAs, we evaluated and compared their abundance in EVs and cells from the bone marrow aspirate samples of patients at different stages of the disease (MM and SMM). As shown in Figure 3B, we did not observe differences in the level of these miRNAs in cells from the two clinical conditions (upper panel), while we interestingly observed a significant 
enrichment of miR-129-5p in MM EVs compared to SMM (lower panel). Interestingly, two patients with extensive bone disease release EVs with higher miR-129-5p levels. Overall this result may suggest a selective packaging of miR-129-5p into MM-EVs correlated with pathological grade. The clinical characteristics of patients enrolled in this study are summarized in Supplementary Table S1.

\subsection{MiR-129-5p Level Increases in hMSCs afterEV Incubation}

Considering that, unlike MM, SMM patients do not exhibit lytic bone lesions, in order to identify the miRNAs that could affect bone differentiation, we focused our study on the miRNAs enriched in EV from MM patients. We first assessed the expression levels of these miRNAs in hMSCs after 6 and $24 \mathrm{~h}$ of treatment with MM patient EVs $(n=4)$. To note, three out four EV samples were isolated from patients with extensive bone disease. Interestingly, we found a time-dependent increase of miR-129-5p levels and an increase of miR-146a-5p at 24h (Figure 4A). MiR-146a-5p was previously found in MM EVs and its level increased in MSC after EV treatment. Further, the authors found that the increased level of this miRNA in MSCs led to MM cell growth and migration [48]. Considering the significant increased levels of miR-129-5p among MM EVs (Figure 3B, lower panel) and the increased amount of the miRNA in hMSCs after EV incubation, we decided to focus on miR-129-5p. To correlate the increased level of the miRNA in target cells with its delivery by EVs, we analyzed the miRNA precursor level. As shown in Figure 4B, we didn't observe any difference in the expression of the pri-miR-129, thus suggesting an EV-mediated transport of the miRNA from MM cells to hMSCs rather than an EV-mediated induction.

A
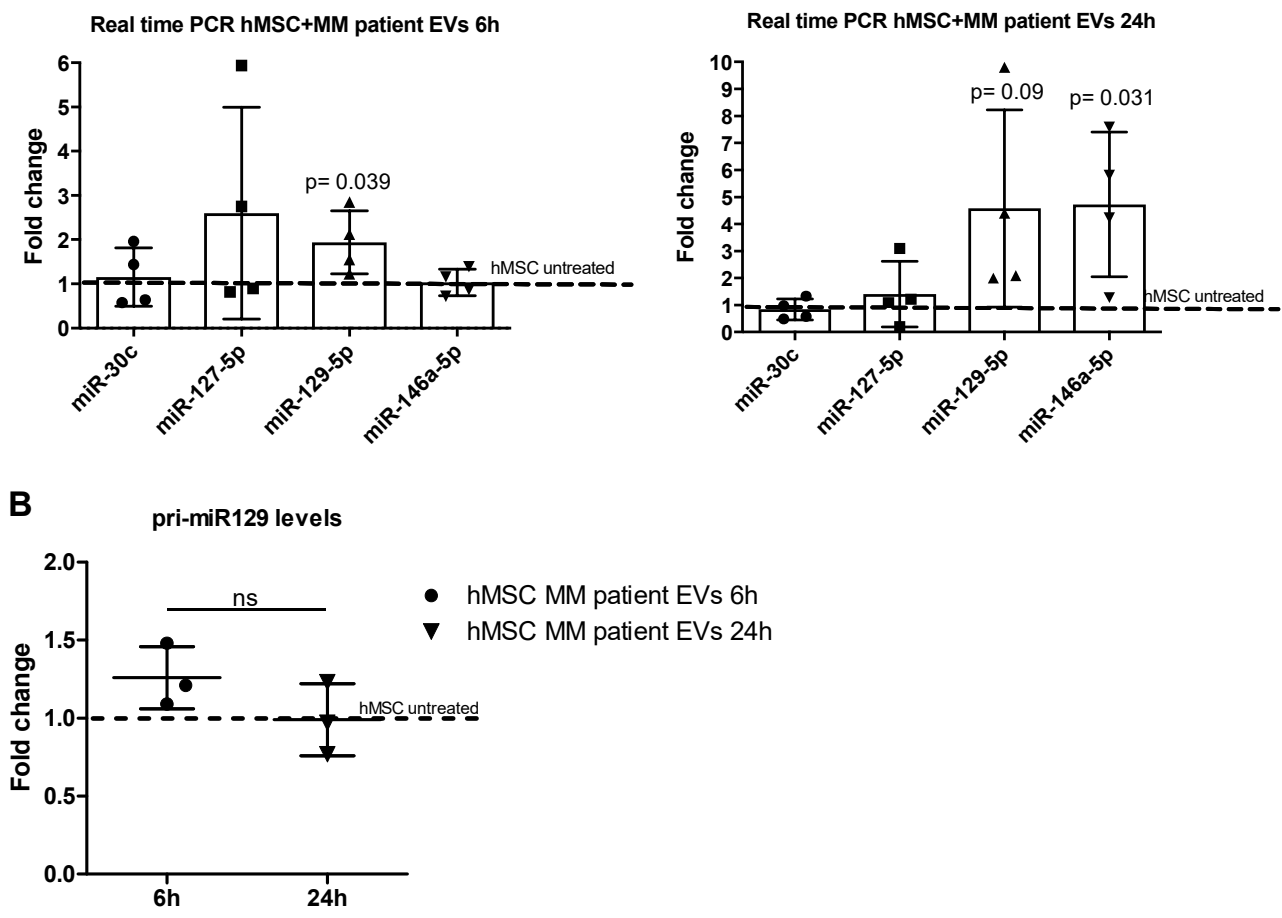

Figure 4. (A) Real-time PCR analyses for miR-30c, miR-127-5p, miR-129-5p and miR-146a-5p were performed on hMSCs incubated for 6 (left panel) and 24h (right panel) with EVs from the bone marrow plasma of MM patients $(n=4)$. Data were normalized for snoU6. Values are expressed as Fold Change in miRNA expression that occurred in cells treated with EVs versus untreated hMSCs (dotted line). (B) The Real-Time PCR analyses of pri-miR-129 were performed on hMSCs incubated for 6 and 24h with EVs from the bone marrow plasma of MM patients $(n=3)$. Data were normalized for $\beta$-actin and values are expressed as Fold Change in the pri-miRNA expression that occurred in cells treated with EVs versus untreated hMSCs. The statistical significance of the differences was analyzed using a two-tailed Student's $t$-test. 


\subsection{MiR-129-5p Inhibits ALPL Expression in hMSCs}

Three publicly available bioinformatics databases (TargetScan, microRNA.org, and miRWalk) were used to analyze genes targeted by miR-129-5p (Figure 5A, upper panel). Among the miRNA predicted targets, we found ALPL (Figure 5A, lower panel), an early marker of hMSCsosteogenic differentiation, whose down-regulation was largely associated with MM EVs-mediated osteogenic inhibition [21,23,24]. To investigate a possible role of miR-129-5p on the EV-mediated osteogenic inhibition of hMSCs, and in particular, on ALPL expression, we transfected hMSCs with the miRNA mimic (Supplementary Figure S1) and subsequently analyzed ALPL levels. We found a reduction of the expression of ALPL both at the mRNA (Figure 5B) and the protein level (Figure 5C).

A

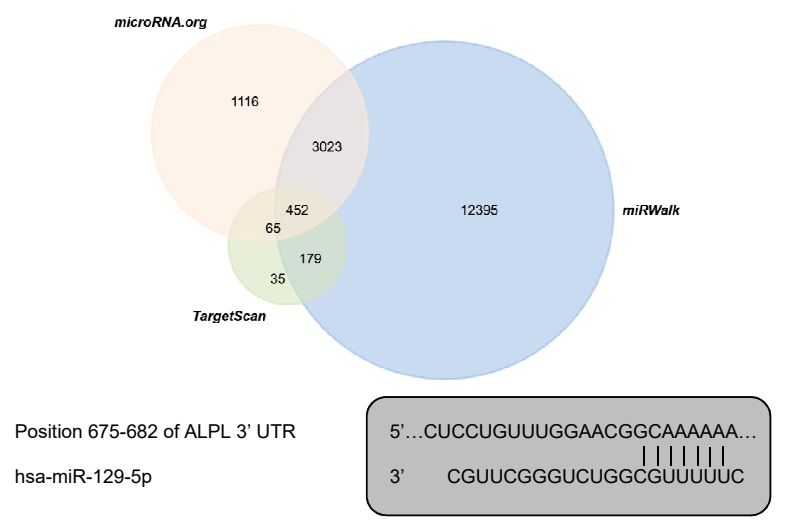

B Real-Time PCR ALPL

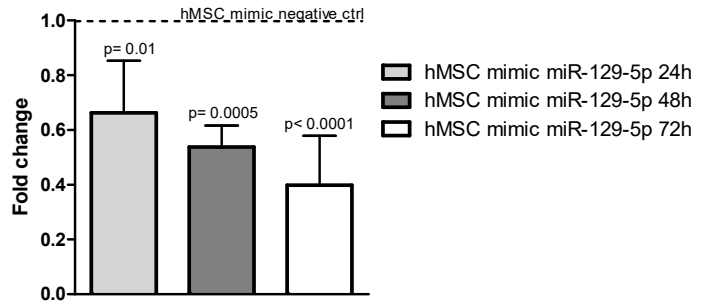

c

ELISA ALPL

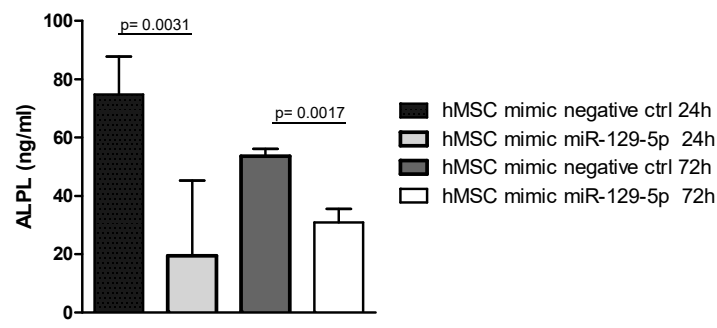

Figure 5. (A, upper panel) The target genes of hsa-miR-129-5p were predicted using three different bioinformatics databases (Target scan, miRWalk and microRNA.org). TheVenn diagram was generated using the FunRich tool available online. (A, lower panel) The sequence alignment between miR-129-5p and the 3'-UTR of ALPL mRNA predicted by TargetScan. (B) The Real-time PCR analysis of ALPL in hMSCs transfected for 24, 48 and 72h with miR-129-5p mimic. Data were normalized for $\beta$-actin. Values are expressed as Fold Change in gene expression that occurred in cells transfected with miR-129-5p mimic versus hMSCs transfected with mimic negative ctrl for each time point (dotted line). The statistical significance of the differences was analyzed using a two-tailed Student's $t$-test. (C) ALPL release was quantified by ELISA in the supernatant of hMSCs transfected for 24 and $72 \mathrm{~h}$ with miR-129-5p mimic and with mimic negative ctrl. Values are reported as ALPL concentration in $\mathrm{ng} / \mathrm{mL}$. The statistical significance of the differences was analyzed using a two-tailed Student's $t$-test. 


\subsection{MiR-129-5p and MM EVs Inhibit the Transcription Factor SP1 Expression in hMSCs}

Starting from this data, we next investigated the other targets of miR 129-5p by using the publicly available bioinformatics tool miRTargetLink Human (https://ccb-web.cs.uni-saarland.de/ mirtargetlink/) [49]. In Figure 6A, the central node represents miR-129-5p, surrounded by the validated targets with strong (e.g., luciferase assay in green) and weak (e.g., microarray in blue) evidence and the predicted targets in yellow. Among the validated target with strong evidence (Figure 6A, right panel), we found the transcription factor Sp1, largely described as a positive modulator of OB differentiation [33,50-52]; it cooperates with Osterix [51,53], and is a transcriptional enhancer of ALPL. Several studies have reported that Sp1 expression is downregulated in cells overexpressing miR-129-5p [54,55]. Therefore, we evaluated Sp1 expression in hMSCs transfected with miR-129-5p mimic and we found that, also in hMSCs, Sp1 is downregulated by miR-129-5p overexpression (Figure 6B). According to this evidence, and to the described role of $\mathrm{Sp} 1$ as a positive modulator of osteogenic differentiation of hMSCs, we evaluated the transcription factor levels in hMSCs treated with EVs from MM patients. We observed that Sp1 expression is reduced in target cells treated for 10 days with EVs, both at mRNA (Figure 6C) and protein (Figure 6D) level. Overall, these data indicated in Sp1 modulation a new mechanism by which MM EVs may inhibit hMSCs osteogenic differentiation.
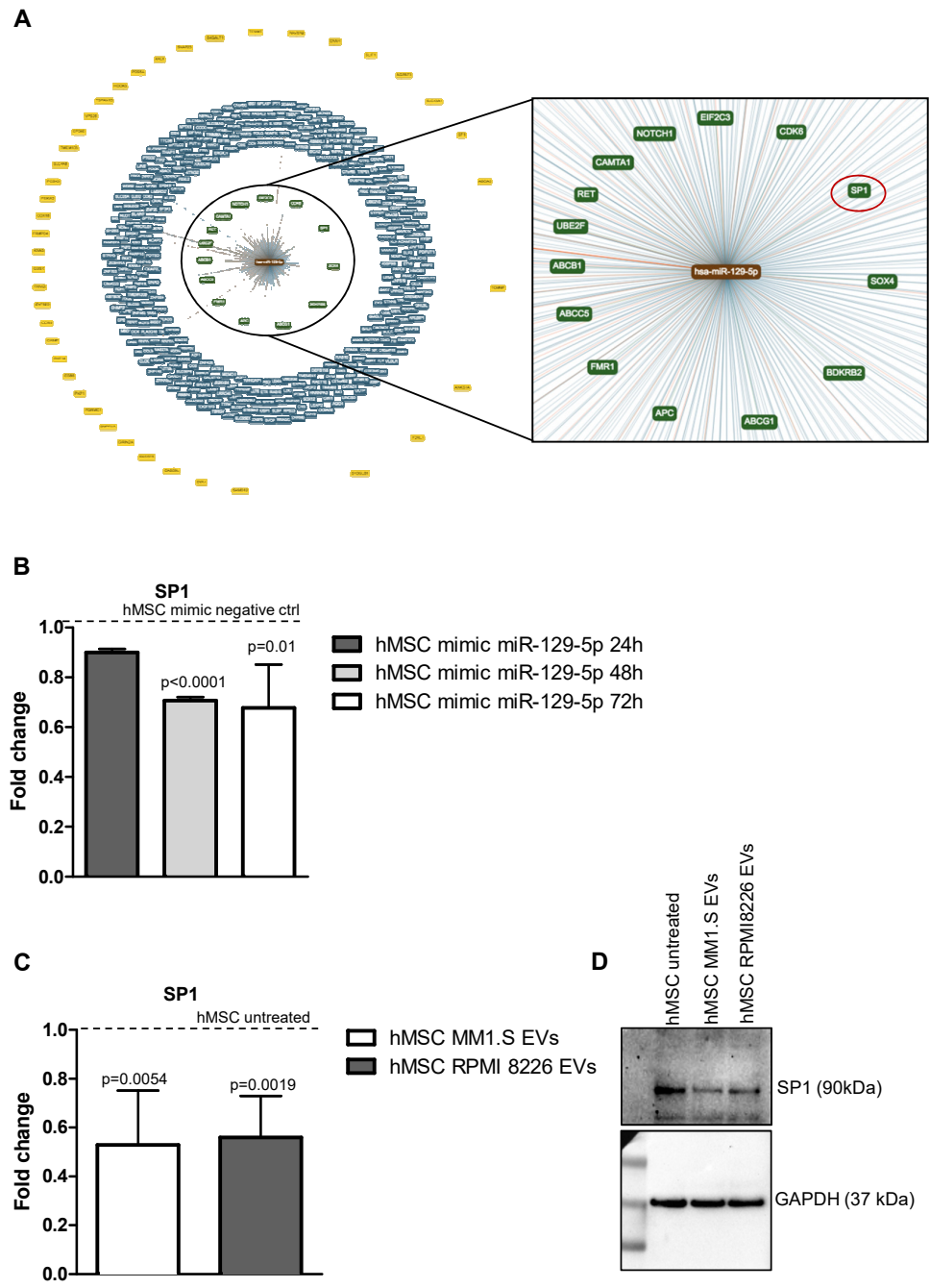

Figure 6. (A) The target and predicted genes of hsa-miR-129-5p were analyzed by the bioinformatics tool miRTargetLink Human. The central node represents miR-129-5p, surrounded by the validated target with strong (green) and weak (blue) evidence and the predicted targets in yellow. (B) The Real-time PCR analysis of Sp1 in hMSCs transfected for 24, 48 and 72h with miR-129-5p mimic. Data were normalized 
for $\beta$-actin. Values are expressed as Fold Change in gene expression that occurred in cells transfected with miR-129-5p mimic versushMSCs transfected with mimic negative ctrl for each time point (dotted line). The statistical significance of the differences was analyzed using a two-tailed Student's t-test. (C) The Real-time PCR analysis of Sp1 was performed on hMSCs maintained in the osteogenic medium after 10 days of treatment with MM1.S and RMPI 8226-derived EVs. Data were normalized for $\beta$-actin and values are expressed as Fold Change in gene expression that occurred in cells treated with EVs versus untreated hMSCs (dotted line). The statistical significance of the differences was analyzed using a two-tailed Student's t-test. (D) The expression of SP1 was evaluated by western blotting in hMSCs treated for 10 days with MM1.S and RPMI 8226-derive EVs.

Interestingly, a bioinformatics analysis, focusing this time on the transcription factor Sp1 (central node in Figure 7, left panel), revealed that among the miRNAs that target Sp1 with strong evidence, the $50 \%$ were identified by us in MM1.S EVs by TaqMan real-time PCR-based miRNA array card (Figure 7, right panel, red circle). Altogether these data suggest that several mediators of the osteogenic differentiation of hMSCs are modulated by MM EVs and that, together with miR-129-5p, other miRNAs, delivered by EVs may cooperate to decrease the osteogenic potential of hMSCs.

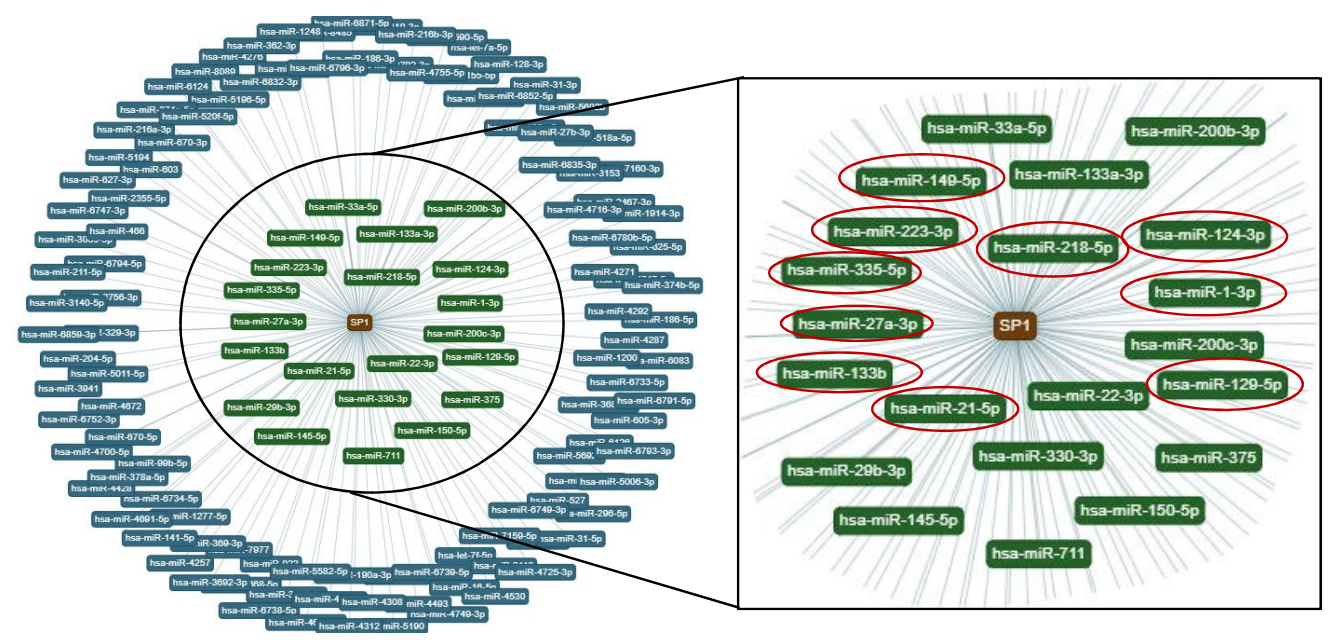

Figure 7. The miRNAs that target $\mathrm{Sp} 1$ were analyzed by the bioinformatics tool miRTargetLink Human. The central node represents Sp1, surrounded by the miRNAs that target Sp1 with strong (green) and weak (blue) evidence. Red circles indicated miRNAs that target Sp1 and that were identified in MM1.S-EVs.

\section{Discussions}

Multiple lines of evidence define the involvement of EVs in MM progression as they can act on several cellular targets and at different levels of disease progression [12-19]. In particular, recent findings have highlighted the role of EVs as inducers of MM-osteolytic bone disease [21-27].

Although some of the mediators of this effect have been identified, a further description of the content of the EVs and the identification of additional molecules responsible for the EV-mediated activation of OCs and the inhibition of OBs would be useful to develop new diagnostic and prognostic markers in MM management. In the current study, we assess if miRNAs transported by EVs may have a role in the inhibition of osteoblast differentiation.

OBs are derived from bone marrow MSCinduced to differentiate bymicro-environmental cues represented by cytokines and extracellular matrix components [56]. In MM patients, the osteogenic ability of mesenchymal progenitors to differentiate to mature OBs is disrupted [57-59], as evidenced by the decrease in the levels of Osterix, the major osteoblast transcriptional activator, and of the bone formation markers, i.e., ALPL and Collagen type I $\alpha 1$ chain [60-62]. In this context, we found that MM-EVs strongly downregulate the expression of these three markers actively participating in the inhibition of the first differentiation steps of mesenchymal cells. 
It is already well known that EVs contain several species of non-coding RNAs including miRNAs that can be carried and transferred to target cells, thus affecting their phenotype [63]. Here, we found that many of the miRNAs identified in MM EVs have been previouslycorrelated to the inhibition of osteogenic differentiation markers and that the levels of the miR-129-5p are correlated with the pathological grade of MM. Of note, miR-129-5p contains the hEXO motif, a short sequence previously identified by Santangelo et al. which is recognized by the RNA-Binding Protein SYNCRIP, leading to the exosomal enrichment of some miRNAs [64]. This observation enforces the hypothesis of a selective packaging for miR-129-5p.

A very interesting aspect emerging from the analysis on patient samples is that, since the occurrence of MM is often preceded by the asymptomatic plasma cell proliferative disorder (SMM) [65], vesicle-associated miR-129-5p may represent a new biomarker for the risk stratification; further studies, as well as the increase in the number of enrolled patients, are needed to validate this point.

Concomitantly, by mimic transfection, we investigated the effect of miR-129-5p on hMSCs by focusing on the predicted and validated osteogenic markers. MiR-129-5p was found to bind to the 3'UTR of COL1A1 mRNA in gastric cancer [42,44] and hepatic stellate cells [43]. Consistent with these findings, we observed a downregulation of COL1A1 mRNA in hMSCs transfected with miR129-5p mimics (data not shown). The decrease in ALPL, induced by EVs, and specifically by miR-129-5p, supports the role of EV-miRNAs in MM bone disease.In fact, alkaline phosphatase is decreased in the serum of patients with MM bone involvement [66], while an increase in its level, in patients treated with bortezomib, was associated with treatment response [67].

Once in hMSCs, miR-129-5p can affect cell phenotype by targeting different transcripts; bioinformatics analyses revealed that several validated targets of miR-129-5p are involved in bone remodeling pathways, such as the ATP-binding cassette transporters [68,69] and Notch1 [70,71]. Of note, among the validated targets, we found the transcription factor Sp1 [54,55]. Sp1 was previously described as a positive regulator of OB differentiation [33,50-52], in fact, its downregulation in a human fetal osteoblastic cell line (hFOB) resulted in reduced expression of Frizzled-1 and a decrease in ALP activity, while its overexpression increased osteosarcoma cell Saos2 mineralization [33]. Further, Sp1enhances Runx2 promoter activity during osteogenesis progression [72].

Our study highlighted a novel mechanism by which MM EVs can inhibit osteoblast differentiation, by reducing the expression of Sp1 in hMSCs. Interestingly, focusing on the validated miRNAs that target Sp1, half of them are present in MM-EVs and are known to have a role in osteogenic differentiation of MSC. For example, miR-21-5p inhibited the osteogenic differentiation in Periodontal Ligament Stem Cells by targeting Smad5 [73]. In addition, its presence in osteosarcoma exosomes was correlated with bone resorption activity of pre-osteoclast cells. The miR-27a-3p expression is upregulated in osteosarcoma cell lines compared with normal human osteoblastic cells [74]. The evidence that different molecular players, with the same target, are delivered by EVs, emphasizes the ability of EVs to strongly affect the phenotype of recipient cells. Further investigation are needed to deeply investigate the in vivo contribution of Sp1 in the osteogenic differentiation of MSC in patient affected by MM. At this stage, consistent with previous data, we correlated the MM-EV miRNA content with the dimished Sp1 levels in hMSC. To date, Sp1 expression was correlated to MM cell proliferation $[75,76]$ but its expression in hMSC during MM bone disease development still need to be explored.

In conclusion, our study provides new insights into the role of MM EVs in inhibiting the osteogenic differentiation of hMSCs focusing initially on the content of EVs. Then, taking into consideration the increase in miR-129 levels in hMSCs after EV treatment, we unveiled a novel mechanism, by which MM EVs may act on osteoblast differentiation. 


\section{Materials and Methods}

\subsection{Cell Cultures}

MM cell lines, MM1.S and RPMI 8226 were purchased from ATCC (Manassas, VA, USA) and cultured in RPMI 1640 medium (Euroclone, UK) supplemented with 10\% fetal bovine serum (FBS, Euroclone s.p.a., Milan, Italy). FBS was previously ultracentrifuged to deplete it from exosomes (exosome- free FBS). Human Mesenchymal Stem Cells (hMSCs) were obtained from Lonza (Lonza, Walkersville, MD, USA) and grown in Mesenchymal Stem Cell growth medium (MSCGM BulletKit ${ }^{\mathrm{TM}}$, Lonza, Walkersville, MD, USA) to maintain them into an undifferentiated condition and in Mesenchymal Stem Cell Osteogenic Differentiation Medium to induce osteogenic differentiation (MSC Osteogenic Differentiation BulletKit ${ }^{\mathrm{TM}}$, Lonza). Cells were routinely tested for mycoplasma contamination using N-Garde Kit For Mycoplasma Detection (Euroclone).

\subsection{Purification of Primary Plasma Cells}

Human primary plasma cells were isolated from the bone marrow aspirates of patients affected by MM patients $(n=7)$ and by Smouldering Multiple Myeloma (SMM, $n=5)$ in accordance with the Declaration of Helsinki guidelines and the Ethics committee of the Hospital of the University of Palermo (date of approval 14/11/2018, report $\mathrm{N}^{\circ} 10 / 2018$ ). Bone marrow blood sampleswere diluted with PBS and mononuclear cells were separated by Ficoll-Paque gradient centrifugation (GE Helthcare-Bio Science, Uppsala, Sweden). The collected cells were pelleted and stored for further RNA isolation.

\subsection{Extracellular Vesicle Isolation}

Extracellular vesicles (EVs) were isolated from the conditioned culture medium of MM1.S and RPMI 8226 after a $48 \mathrm{~h}$ culture period in the presence of exosome- free FBS. EVs were collected by differential centrifugation; conditioned culture medium was centrifuged subsequently for $5 \mathrm{~min}$ at $300 \times g, 15 \mathrm{~min}$ at $3000 \times g$, and $30 \mathrm{~min}$ at $10,000 \times g$ and then ultracentrifuged for $105 \mathrm{~min}$ at 100,000× $g$ in a Type $70 \mathrm{Ti}$, fixed angle rotor. EVs were also isolated from the bone marrow (BM) plasma of patients affected by MM $(n=7)$ and by SMM $(n=5)$. All patients provided written informed consent in accordance with the Declaration of Helsinki. The Ethics Committee of the Hospital of the University of Palermo (Italy) approved the study. EVs were isolated from human plasma and prepared as described above. EV pellets were washed and suspended in PBS, and vesicle protein content was determined by the Bradford assay.

\subsection{Internalization of MM-Derived EVs by hMSCs}

MM1.S and RPMI 8226 EVs were labeled with PKH26 Red Fluorescent Cell Linker Kits (Sigma-Aldrich, USA) following the datasheet information. EVs, collected as previously described, were incubated for $15 \mathrm{~min}$ at room temperature with PKH26 dye previously diluted in the diluent C solution. Labeled EVs were washed in PBS; the pellets were suspended in the medium and incubated with hMSCs, grown on coverslips, for $4 \mathrm{~h}$. After incubation, hMSCs were fixed with PFA $4 \%$, permeabilized with $0.1 \%$ TritonX-100, stained with Actin Green (Molecular Probes, Life Technologies, Carlsbad, CA, USA) that binds actin with high affinity. Nuclei were then stained with Hoechst (Molecular Probes, Life Technologies, Carlsbad, CA, USA). Preparations were analyzed by confocal microscopy (Nikon A1).

\section{5. hMSCs Treatment with EVS}

Cells were plated in 12-well plates in the basal Mesenchymal Stem Cell growth medium; $24 \mathrm{~h}$ after seeding, when cells were $70 \%$ confluent, the media was replaced with the Mesenchymal Stem Cell Osteogenic Differentiation Medium. Cells were treated for 10 days with EVs from MM1.S and RPMI $8226(50 \mu \mathrm{g} / \mathrm{mL})$ to assess the effect of EVs on the osteogenic differentiation of hMSCs; the media 
were changed every 3 days. Cells were also treated for 6 and $24 \mathrm{~h}$ with EVs from plasma samples to further evaluate the miRNA expression levels.

\subsection{MiRNA Expression Profiling}

RNA was extracted from MM1.S EVs by using the IllustraRNAspin Mini Isolation Kit (GE Healthcare, Little Chalfont, Buckinghamshire, UK) according to the manufacturer's recommendations. $200 \mathrm{ng}$ of total RNA was reverse transcribed using Megaplex ${ }^{\mathrm{TM}}$ RT Primers Human Pool A (Life Technologies, Carlsbad, CA, USA) according to the manufacturer's instructions. The reaction was carried out at $16^{\circ} \mathrm{C}$ for $2 \mathrm{~min}, 42^{\circ} \mathrm{C}$ for $1 \mathrm{~min}, 50^{\circ} \mathrm{C}$ for $1 \mathrm{~s}$ for 40 cycles, $85^{\circ} \mathrm{C}$ for 5 min then hold at $4{ }^{\circ} \mathrm{C}$.

To identify the miRNA profile of MM1.S EVs, real-time TaqMan PCR was carried out by using the TaqMan microRNA array Human Pool A cards containing 384 different miRNAs (Thermo Fisher Scientific, Waltham, MA, USA). The cDNA obtained in the previous step was diluted, mixed with TaqMan Gene Expression Master Mix and loaded into each of the eight fill ports on the TaqMan ${ }^{\circledR}$ Human MicroRNA Array A (Life Technologies, Carlsbad, CA, USA). The array was centrifuged twice at $1200 \mathrm{rpm}$ for $1 \mathrm{~min}$ and run on ABI-PRISM 7900 HT Sequence Detection System (Applied Biosystems, Foster City, CA, USA) using the manufacturer's recommended program. Ct values for each miRNA were normalized using thereferencesnoU6 RNA. Relative miRNA levels were expressed as $2^{\wedge} \Delta \mathrm{Ct}$. The HeatMap has been generated using Matlab 2019a software. Color scaling is set to log scale.

\subsection{Cell Transfection}

Transfection of miRNA mimic in hMSCs was performed using the Lipofectamin 3000 Transfection Reagent (Thermo Fisher Scientific) according to the manufacturer's instructions. Cells were plated in 12-well plates; $24 \mathrm{~h}$ after seeding, when cells were $70 \%$ confluent, cells were transfected with 30pmoles/mL of hsa-129-5p mimic (cat.number 4464066, Life Technologies), or scrambled negative control (4464058, Life Technologies). Twenty-four, 48 and $72 \mathrm{~h}$ after transfection, the medium was collected and the cells processed for RNA isolation.

\subsection{RNA Isolation and Real-Time PCR}

RNA was extracted using the commercially available IllustraRNAspin Mini Isolation Kit (GE Healthcare, Little Chalfont, Buckinghamshire, UK), according to the manufacturer's instructions. RNA was isolated from cell lines, primary cells as well as EVs. Total RNA was reverse transcribed to cDNA using the High Capacity cDNA Reverse Transcription Kit (Applied Biosystems, Foster City, CA, USA). For quantitative Sybergreen real-time PCR, the reaction was carried out in a total volume of $20 \mu$ Lcontaining $2 \times$ SYBR Green I Master Mix (Applied Biosystems), $2 \mu$ LcDNA, and $300 \mathrm{nM}$ forward and reverse primers. The oligonucleotides used were reported in the Table 1 below:

Table 1. Primer sequence used for gene expression analysis.

\begin{tabular}{ccc}
\hline Gene & Primer Forward & Primer Reverse \\
\hline B-Actin & TCCCTTGCCATCCTAAAAAGCCACCC & CTGGGCCATTCTTCCTTAGAGAGAAG \\
OSX & TGCTTGAGGAGGAAGTTCAC & AGGTCACTGCCCACAGAGTA \\
ALPL & CCACGTCTTCACATTTGGTG & AGACTGCGCCTGGTAGTTGT \\
COL1A1 & TGTGGATGCCTCTTGGGTATC & TTTTGGCCATCTCTTCCTTCA \\
OCN & AGCAAAGGTGCAGCCTTTGT & GCGCCTGGGTCTCTTCACT \\
SP1 & GCCTCCAGACCATTAACCTCAGT & GCTCCATGATCACCTGGGGCAT \\
\hline
\end{tabular}

For miRNA expression, 10 ng of RNA was reverse transcribed according to the manufacturer's instructions (TaqManMicroRNA Reverse Transcription, Applied Biosystem). Taqman probes, from Applied Biosystems were used to analyze: miR-30c-5p, miR-127-5p, miR-129-5p, miR-146-5p, and U6. Real-time PCR was performed in 48-well plates using the Step-One Real-Time PCR system (Applied 
Biosystems) in duplicated for each data point. Relative changes in the target mRNA content, relative to a housekeeping gene ( $\beta$-actin), and in the target miRNA content, relative to housekeeping U6, were determined with the $\Delta \Delta$ ct Method.

\subsection{ELISA ALPL}

ALPL concentration in the conditioned medium of hMSCs was measured using the ALPL ELISA Kit (MyBioSource), following the manufacturer's protocol. The conditioned medium of hMSCs was medium was collected after 24 or $72 \mathrm{~h}$ of transfection with miR-129-5p mimic. Data were expressed as ALPL concentration in $\mathrm{ng} / \mathrm{mL}$.

\subsection{Western Blotting}

Total proteins from hMSCs cells, treated for 10 days with MM-EVs, were isolated and analyzed by SDS-PAGE followed by western blotting. Antibodies used in the experiments were as follows: anti-SP1 antibody (Abcam) and anti-GAPDH (Santa Cruz Biotechnology, CA, USA).

\subsection{Bioinformatics Tools}

TargetScan [77], miRWalk [78] and microRNA.org [79] bioinformatics databases were used to analyze the predicted target mRNAs of the selected microRNAs. FunRich analysis tool [80] was used to generate a Venn diagram of the relationships between the 3 datasets generated above. miRTargetLink Human [49] was used to generate the miRNA-target interaction network.

\subsection{Statistical Analysis}

Data are reported as mean \pm standard deviation (SD) of 3 or more biological replicates. Statistical analysis was performed using GraphPad Prism software (GraphPad software, Inc, La Jolla, CA). The statistical significance of the differences was analyzed using a two-tailed Student's $t$-test. When the data were not normally distributed, Mann-Whitney test was used. A $p$-value $\leq 0.05$ was considered significant.

\subsection{Ethical statement:}

All subjects gave their informed consent for inclusion before they participated in the study. The study was conducted in accordance with the Declaration of Helsinki; the protocol was approved by the Ethics Committee of the Hospital of the University of Palermo (date of approval 14/11/2018, report $\left.\mathrm{N}^{\circ} 10 / 2018\right)$.

\section{Conclusions}

In summary, in this study, we have provided evidence of the role of miRNAs, delivered by MMEVs, on the EV-mediated osteogenic inhibition of hMSCs. In particular, we found that MM-EVs contain several miRNAs involved in osteogenic regulation. Among those, miR-129-5p is enriched in MM EVs and is delivered in hMSCs, leading to the downregulation of ALPL and Sp1 (Graphical abstract). Further, our study uncovered the transcription factor Sp1, already described as a positive modulator of hMSCsosteogenic differentiation, as a novel target of MM EVs.

Supplementary Materials: The following are available online at http://www.mdpi.com/2072-6694/12/2/449/s1, Supplementary Table S1: Clinical characteristics of patients affected by MM and SMM; Supplementary Figure S1: Real-time PCR analysis of miR-129-5p in hMSCs transfected for 24, 48 and 72h with miR-129-5p mimic.

Author Contributions: Conceptualization, S.R. and R.A.; Formal analysis, S.R., G.L.B. and G.G.; Funding acquisition, R.A.; Investigation, S.R., O.U., S.P., L.R. and A.D.L.; Resources, M.C. and S.S.; Supervision, R.A.; Writing-Original draft, S.R., A.C. and R.A. All authors have read and agreed to the published version of the manuscript. 
Funding: This work was supported by a grant from the Fondazione AIRC per la Ricerca sul Cancro to Riccardo Alessandro (grant $n^{\circ} 18783$ ). Stefania Raimondo was supported by a "FIRC" (Fondazione Italiana per la Ricerca sul Cancro) fellowship (project $\left.n^{\circ} 17927\right)$.

Conflicts of Interest: The authors declare no conflict of interest.

\section{References}

1. Kazandjian, D. Multiple myeloma epidemiology and survival: A unique malignancy. Semin. Oncol. 2016, 43, 676-681. [CrossRef] [PubMed]

2. Mateos, M.V.; Landgren, O. Mgus and smoldering multiple myeloma: Diagnosis and epidemiology. Cancer Treat. Res. 2016, 169, 3-12. [PubMed]

3. Kyle, R.A.; Gertz, M.A.; Witzig, T.E.; Lust, J.A.; Lacy, M.Q.; Dispenzieri, A.; Fonseca, R.; Rajkumar, S.V.; Offord, J.R.; Larson, D.R.; et al. Review of 1027 patients with newly diagnosed multiple myeloma. Mayo Clin. Proc. 2003, 78, 21-33. [CrossRef]

4. Terpos, E.; Ntanasis-Stathopoulos, I.; Gavriatopoulou, M.; Dimopoulos, M.A. Pathogenesis of bone disease in multiple myeloma: From bench to bedside. Blood Cancer J. 2018, 8, 7. [CrossRef]

5. Hameed, A.; Brady, J.J.; Dowling, P.; Clynes, M.; O'Gorman, P. Bone disease in multiple myeloma: Pathophysiology and management. Cancer Growth Metastasis 2014, 7, 33-42. [CrossRef]

6. Noll, J.E.; Williams, S.A.; Tong, C.M.; Wang, H.; Quach, J.M.; Purton, L.E.; Pilkington, K.; To, L.B.; Evdokiou, A.; Gronthos, S.; et al. Myeloma plasma cells alter the bone marrow microenvironment by stimulating the proliferation of mesenchymal stromal cells. Haematologica 2014, 99, 163-171. [CrossRef]

7. Wang, J.; Liu, S.; Li, J.; Zhao, S.; Yi, Z. Roles for mirnas in osteogenic differentiation of bone marrow mesenchymal stem cells. Stem. Cell Res. Ther. 2019, 10, 197. [CrossRef]

8. Arfat, Y.; Xiao, W.Z.; Ahmad, M.; Zhao, F.; Li, D.J.; Sun, Y.L.; Hu, L.; Zhihao, C.; Zhang, G.; Iftikhar, S.; et al. Role of micrornas in osteoblasts differentiation and bone disorders. Curr. Med. Chem. 2015, 22, 748-758. [CrossRef]

9. Peng, S.; Gao, D.; Gao, C.; Wei, P.; Niu, M.; Shuai, C. Micrornas regulate signaling pathways in osteogenic differentiation of mesenchymal stem cells (review). Mol. Med. Rep. 2016, 14, 623-629. [CrossRef]

10. Raposo, G.; Stahl, P.D. Extracellular vesicles: A new communication paradigm? Nat. Rev. Mol. Cell Biol. 2019, 20, 509-510. [CrossRef]

11. Thery, C.; Witwer, K.W.; Aikawa, E.; Alcaraz, M.J.; Anderson, J.D.; Andriantsitohaina, R.; Antoniou, A.; Arab, T.; Archer, F.; Atkin-Smith, G.K.; et al. Minimal information for studies of extracellular vesicles 2018 (misev2018): A position statement of the international society for extracellular vesicles and update of the misev2014 guidelines. J. Extracell. Vesicles 2018, 7, 1535750. [CrossRef]

12. Moloudizargari, M.; Abdollahi, M.; Asghari, M.H.; Zimta, A.A.; Neagoe, I.B.; Nabavi, S.M. The emerging role of exosomes in multiple myeloma. Blood Rev. 2019, 38, 100595. [CrossRef] [PubMed]

13. Colombo, M.; Giannandrea, D.; Lesma, E.; Basile, A.; Chiaramonte, R. Extracellular vesicles enhance multiple myeloma metastatic dissemination. Int. J. Mol. Sci. 2019, 20, 3236. [CrossRef]

14. Wang, J.; De Veirman, K.; Faict, S.; Frassanito, M.A.; Ribatti, D.; Vacca, A.; Menu, E. Multiple myeloma exosomes establish a favourable bone marrow microenvironment with enhanced angiogenesis and immunosuppression. J. Pathol. 2016, 239, 162-173. [CrossRef]

15. Zarfati, M.; Avivi, I.; Brenner, B.; Katz, T.; Aharon, A. Extracellular vesicles of multiple myeloma cells utilize the proteasome inhibitor mechanism to moderate endothelial angiogenesis. Angiogenesis 2019, 22, 185-196. [CrossRef] [PubMed]

16. Liu, Y.; Zhu, X.J.; Zeng, C.; Wu, P.H.; Wang, H.X.; Chen, Z.C.; Li, Q.B. Microvesicles secreted from human multiple myeloma cells promote angiogenesis. ActaPharmacol. Sin. 2014, 35, 230-238. [CrossRef] [PubMed]

17. Li, B.; Hong, J.; Hong, M.; Wang, Y.; Yu, T.; Zang, S.; Wu, Q. Pirna-823 delivered by multiple myeloma-derived extracellular vesicles promoted tumorigenesis through re-educating endothelial cells in the tumor environment. Oncogene 2019, 38, 5227-5238. [CrossRef] [PubMed]

18. Arendt, B.K.; Walters, D.K.; Wu, X.; Tschumper, R.C.; Jelinek, D.F. Multiple myeloma dell-derived microvesicles are enriched in cd147 expression and enhance tumor cell proliferation. Oncotarget 2014, 5, 5686-5699. [CrossRef] 
19. Wang, J.; De Veirman, K.; De Beule, N.; Maes, K.; De Bruyne, E.; Van Valckenborgh, E.; Vanderkerken, K.; Menu, E. The bone marrow microenvironment enhances multiple myeloma progression by exosome-mediated activation of myeloid-derived suppressor cells. Oncotarget 2015, 6, 43992-44004. [CrossRef]

20. Pourhanifeh, M.H.; Mahjoubin-Tehran, M.; Shafiee, A.; Hajighadimi, S.; Moradizarmehri, S.; Mirzaei, H.; Asemi, Z. Micrornas and exosomes: Small molecules with big actions in multiple myeloma pathogenesis. IUBMB Life 2019. [CrossRef]

21. Raimondo, S.; Saieva, L.; Vicario, E.; Pucci, M.; Toscani, D.; Manno, M.; Raccosta, S.; Giuliani, N.; Alessandro, R. Multiple myeloma-derived exosomes are enriched of amphiregulin (areg) and activate the epidermal growth factor pathway in the bone microenvironment leading to osteoclastogenesis. J. Hematol. Oncol. 2019, 12, 2. [CrossRef] [PubMed]

22. Raimondi, L.; De Luca, A.; Amodio, N.; Manno, M.; Raccosta, S.; Taverna, S.; Bellavia, D.; Naselli, F.; Fontana, S.; Schillaci, O.; et al. Involvement of multiple myeloma cell-derived exosomes in osteoclast differentiation. Oncotarget 2015, 6, 13772-13789. [CrossRef] [PubMed]

23. Faict, S.; Muller, J.; De Veirman, K.; De Bruyne, E.; Maes, K.; Vrancken, L.; Heusschen, R.; De Raeve, H.; Schots, R.; Vanderkerken, K.; et al. Exosomes play a role in multiple myeloma bone disease and tumor development by targeting osteoclasts and osteoblasts. Blood Cancer J. 2018, 8, 105. [CrossRef] [PubMed]

24. Liu, Z.; Liu, H.; Li, Y.; Shao, Q.; Chen, J.; Song, J.; Fu, R. Multiple myeloma-derived exosomes inhibit osteoblastic differentiation and improve il-6 secretion of bmscs from multiple myeloma. J. Investig. Med. 2019. [CrossRef] [PubMed]

25. Zhang, L.; Lei, Q.; Wang, H.; Xu, C.; Liu, T.; Kong, F.; Yang, C.; Yan, G.; Sun, L.; Zhao, A.; et al. Tumor-derived extracellular vesicles inhibit osteogenesis and exacerbate myeloma bone disease. Theranostics 2019, 9, 196-209. [CrossRef]

26. Zhang, L.; Li, G.; Wang, K.; Wang, Y.; Dong, J.; Wang, H.; Xu, L.; Shi, F.; Cao, X.; Hu, Z.; et al. Mir-30 family members inhibit osteoblast differentiation by suppressing runx2 under unloading conditions in mc3t3-e1 cells. Biochem. Biophys. Res. Commun. 2020, 522, 164-170. [CrossRef] [PubMed]

27. Li, B.; Xu, H.; Han, H.; Song, S.; Zhang, X.; Ouyang, L.; Qian, C.; Hong, Y.; Qiu, Y.; Zhou, W.; et al. Exosome-mediated transfer of lncrunx2-as1 from multiple myeloma cells to mscs contributes to osteogenesis. Oncogene 2018, 37, 5508-5519. [CrossRef]

28. Pinzone, J.J.; Hall, B.M.; Thudi, N.K.; Vonau, M.; Qiang, Y.W.; Rosol, T.J.; Shaughnessy, J.D., Jr. The role of dickkopf-1 in bone development, homeostasis, and disease. Blood 2009, 113, 517-525. [CrossRef]

29. Deniaud, E.; Baguet, J.; Mathieu, A.L.; Pages, G.; Marvel, J.; Leverrier, Y. Overexpression of sp1 transcription factor induces apoptosis. Oncogene 2006, 25, 7096-7105. [CrossRef]

30. Haidweger, E.; Novy, M.; Rotheneder, H. Modulation of sp1 activity by a cyclin a/cdk complex. J. Mol. Biol. 2001, 306, 201-212. [CrossRef]

31. Li, L.; Davie, J.R. The role of sp1 and sp3 in normal and cancer cell biology. Ann. Anat. 2010, 192, $275-283$. [CrossRef]

32. Zhang, X.; Li, R.; Qin, X.; Wang, L.; Xiao, J.; Song, Y.; Sheng, X.; Guo, M.; Ji, X. Sp1 plays an important role in vascular calcification both in vivo and in vitro. J. Am. Heart Assoc. 2018, 7, e007555. [CrossRef] [PubMed]

33. Yu, S.; Yerges-Armstrong, L.M.; Chu, Y.; Zmuda, J.M.; Zhang, Y. Transcriptional regulation of frizzled-1 in human osteoblasts by sp1. PLoS ONE 2016, 11, e0163277. [CrossRef] [PubMed]

34. Wang, R.; Xu, B.; Xu, H. Tgf-beta1 promoted chondrocyte proliferation by regulating sp1 through msc-exosomes derived mir-135b. Cell Cycle 2018, 17, 2756-2765. [CrossRef] [PubMed]

35. Chen, L.; Holmstrom, K.; Qiu, W.; Ditzel, N.; Shi, K.; Hokland, L.; Kassem, M. Microrna-34a inhibits osteoblast differentiation and in vivo bone formation of human stromal stem cells. Stem Cells 2014, 32, 902-912. [CrossRef]

36. Kang, H.; Yang, K.; Xiao, L.; Guo, L.; Guo, C.; Yan, Y.; Qi, J.; Wang, F.; Ryffel, B.; Li, C.; et al. Osteoblast hypoxia-inducible factor-1alpha pathway activation restrains osteoclastogenesis via the interleukin-33-microrna-34a-notch1 pathway. Front. Immunol. 2017, 8, 1312. [CrossRef]

37. Belaya, Z.E.; Grebennikova, T.A.; Melnichenko, G.A.; Nikitin, A.G.; Solodovnikov, A.G.; Brovkina, O.I.; Grigoriev, A.U.; Rozhinskaya, L.Y.; Dedov, I.I. Effects of endogenous hypercortisolism on bone mrna and microrna expression in humans. Osteoporos. Int. 2018, 29, 211-221. [CrossRef] 
38. Zhang, Y.; Xie, R.L.; Croce, C.M.; Stein, J.L.; Lian, J.B.; van Wijnen, A.J.; Stein, G.S. A program of micrornas controls osteogenic lineage progression by targeting transcription factor runx2. Proc. Natl. Acad. Sci. USA 2011, 108, 9863-9868. [CrossRef]

39. Tu, M.; Li, Y.; Zeng, C.; Deng, Z.; Gao, S.; Xiao, W.; Luo, W.; Jiang, W.; Li, L.; Lei, G. Microrna-127-5p regulates osteopontin expression and osteopontin-mediated proliferation of human chondrocytes. Sci. Rep. 2016, 6, 25032. [CrossRef]

40. Liang, J.; Xu, L.; Zhou, F.; Liu, A.M.; Ge, H.X.; Chen, Y.Y.; Tu, M. Malat1/mir-127-5p regulates osteopontin (opn)-mediated proliferation of human chondrocytes through pi3k/akt pathway. J. Cell. Biochem. 2018, 119, 431-439. [CrossRef]

41. Manochantr, S.; Marupanthorn, K.; Tantrawatpan, C.; Kheolamai, P.; Tantikanlayaporn, D.; Sanguanjit, P. The effects of bmp-2, mir-31, mir-106a, and mir-148a on osteogenic differentiation of mscs derived from amnion in comparison with mscs derived from the bone marrow. Stem Cells Int. 2017, 2017, 7257628. [CrossRef] [PubMed]

42. Yang, W.; Pan, Y.; Guan, P.; Li, X.; You, C. Bioinformatics analysis of col1a1 regulated by mir-129-5p as a potential therapeutic target for gastric cancer. Nan Fang Yi Ke Da XueXueBao 2019, 39, 540-546.

43. Chen, Y.; Ou, Y.; Dong, J.; Yang, G.; Zeng, Z.; Liu, Y.; Liu, B.; Li, W.; He, X.; Lan, T. Osteopontin promotes collagen i synthesis in hepatic stellate cells by mirna-129-5p inhibition. Exp. Cell Res. 2018, 362, 343-348. [CrossRef] [PubMed]

44. Wang, Q.; Yu, J. Mir-129-5p suppresses gastric cancer cell invasion and proliferation by inhibiting col1a1. Biochem. Cell Biol. 2018, 96, 19-25. [CrossRef]

45. Musolino, C.; Oteri, G.; Allegra, A.; Mania, M.; D’Ascola, A.; Avenoso, A.; Innao, V.; Allegra, A.G.; Campo, S. Altered microrna expression profile in the peripheral lymphoid compartment of multiple myeloma patients with bisphosphonate-induced osteonecrosis of the jaw. Ann.Hematol. 2018, 97, 1259-1269. [CrossRef]

46. Zhao, J.; Huang, M.; Zhang, X.; Xu, J.; Hu, G.; Zhao, X.; Cui, P. Mir-146a deletion protects from bone loss in ovx mice by suppressing rankl/opg and $\mathrm{m}$-csf in bone microenvironment. J. Bone Miner. Res. 2019, 34, 2149-2161. [CrossRef]

47. Ye, X.; Wang, X.B.; Wang, J.; Ming, J. Effect of microrna-146a on differentiation potential of human bone marrow mesenchymal stem cells. Zhongguo Shi Yan Xue Ye XueZaZhi 2016, 24, 596-601.

48. De Veirman, K.; Wang, J.; Xu, S.; Leleu, X.; Himpe, E.; Maes, K.; De Bruyne, E.; Van Valckenborgh, E.; Vanderkerken, K.; Menu, E.; et al. Induction of mir-146a by multiple myeloma cells in mesenchymal stromal cells stimulates their pro-tumoral activity. Cancer Lett. 2016, 377, 17-24. [CrossRef]

49. Hamberg, M.; Backes, C.; Fehlmann, T.; Hart, M.; Meder, B.; Meese, E.; Keller, A. Mirtargetlink-mirnas, genes and interaction networks. Int. J. Mol. Sci. 2016, 17, 564. [CrossRef]

50. Kim, J.; Lee, H.W.; Rhee, D.K.; Paton, J.C.; Pyo, S. Pneumolysin-induced autophagy contributes to inhibition of osteoblast differentiation through downregulation of $\mathrm{sp} 1$ in human osteosarcoma cells. Biochim. Biophys. Acta Gen. Subj. 2017, 1861, 2663-2673. [CrossRef]

51. Yun-Feng, W.; Matsuo, N.; Sumiyoshi, H.; Yoshioka, H. Sp7/osterix up-regulates the mouse pro-alpha3(v) collagen gene (col5a3) during the osteoblast differentiation. Biochem. Biophys. Res. Commun. 2010, 394, 503-508. [CrossRef] [PubMed]

52. Li, L.; Qiu, X.; Sun, Y.; Zhang, N.; Wang, L. Sp1-stimulated mir-545-3p inhibits osteogenesis via targeting lrp5-activated wnt/beta-catenin signaling. Biochem. Biophys. Res. Commun. 2019, 517, 103-110. [CrossRef] [PubMed]

53. Niger, C.; Lima, F.; Yoo, D.J.; Gupta, R.R.; Buo, A.M.; Hebert, C.; Stains, J.P. The transcriptional activity of osterix requires the recruitment of sp1 to the osteocalcin proximal promoter. Bone 2011, 49, 683-692. [CrossRef] [PubMed]

54. Zhang, J.; Li, S.; Yan, Q.; Chen, X.; Yang, Y.; Liu, X.; Wan, X. Interferon-beta induced microrna-129-5p down-regulates hpv-18 e6 and e7 viral gene expression by targeting sp1 in cervical cancer cells. PLoS ONE 2013, 8, e81366.

55. Wang, W.; Yang, C.; Wang, X.Y.; Zhou, L.Y.; Lao, G.J.; Liu, D.; Wang, C.; Hu, M.D.; Zeng, T.T.; Yan, L.; et al. Microrna-129 and -335 promote diabetic wound healing by inhibiting sp1-mediated mmp-9 expression. Diabetes 2018, 67, 1627-1638. [CrossRef]

56. Sobacchi, C.; Palagano, E.; Villa, A.; Menale, C. Soluble factors on stage to direct mesenchymal stem cells fate. Front. Bioeng. Biotechnol. 2017, 5, 32. [CrossRef] 
57. Roodman, G.D. Osteoblast function in myeloma. Bone 2011, 48, 135-140. [CrossRef]

58. Kassen, D.; Moore, S.; Percy, L.; Herledan, G.; Bounds, D.; Rodriguez-Justo, M.; Croucher, P.; Yong, K. The bone marrow stromal compartment in multiple myeloma patients retains capability for osteogenic differentiation in vitro: Defining the stromal defect in myeloma. Br. J. Haematol. 2014, 167, 194-206. [CrossRef]

59. Adamik, J.; Galson, D.L.; Roodman, G.D. Osteoblast suppression in multiple myeloma bone disease. J. Bone Oncol. 2018, 13, 62-70. [CrossRef] [PubMed]

60. De Matteo, M.; Brunetti, A.E.; Maiorano, E.; Cafforio, P.; Dammacco, F.; Silvestris, F. Constitutive down-regulation of osterix in osteoblasts from myeloma patients: In vitro effect of bortezomib and lenalidomide. Leuk. Res. 2010, 34, 243-249. [CrossRef]

61. Bereziat, V.; Mazurier, C.; Auclair, M.; Ferrand, N.; Jolly, S.; Marie, T.; Kobari, L.; Toillon, I.; Delhommeau, F.; Feve, B.; et al. Systemic dysfunction of osteoblast differentiation in adipose-derived stem cells from patients with multiple myeloma. Cells 2019, 8, 441. [CrossRef] [PubMed]

62. Toscani, D.; Bolzoni, M.; Accardi, F.; Aversa, F.; Giuliani, N. The osteoblastic niche in the context of multiple myeloma. Ann. N. Y. Acad. Sci. 2015, 1335, 45-62. [CrossRef] [PubMed]

63. Ma, P.; Pan, Y.; Li, W.; Sun, C.; Liu, J.; Xu, T.; Shu, Y. Extracellular vesicles-mediated noncoding rnas transfer in cancer. J. Hematol. Oncol. 2017, 10, 57. [CrossRef] [PubMed]

64. Santangelo, L.; Giurato, G.; Cicchini, C.; Montaldo, C.; Mancone, C.; Tarallo, R.; Battistelli, C.; Alonzi, T.; Weisz, A.; Tripodi, M. The rna-binding protein syncrip is a component of the hepatocyte exosomal machinery controlling microrna sorting. Cell Rep. 2016, 17, 799-808. [CrossRef] [PubMed]

65. Blum, A.; Bazou, D.; O'Gorman, P. Smoldering multiple myeloma: Prevalence and current evidence guiding treatment decisions. Blood Lymphat. Cancer 2018, 8, 21-31. [CrossRef] [PubMed]

66. Silbermann, R.; Roodman, G.D. Myeloma bone disease: Pathophysiology and management. J. Bone Oncol. 2013, 2, 59-69. [CrossRef]

67. Zangari, M.; Esseltine, D.; Lee, C.K.; Barlogie, B.; Elice, F.; Burns, M.J.; Kang, S.H.; Yaccoby, S.; Najarian, K.; Richardson, P.; et al. Response to bortezomib is associated to osteoblastic activation in patients with multiple myeloma. Br. J. Haematol. 2005, 131, 71-73. [CrossRef]

68. Takeshita, H.; Kusuzaki, K.; Murata, H.; Suginoshita, T.; Hirata, M.; Hashiguchi, S.; Ashihara, T.; Gebhardt, M.C.; Mankin, H.J.; Hirasawa, Y. Osteoblastic differentiation and p-glycoprotein multidrug resistance in a murine osteosarcoma model. Br. J. Cancer 2000, 82, 1327-1331. [CrossRef]

69. Mourskaia, A.A.; Amir, E.; Dong, Z.; Tiedemann, K.; Cory, S.; Omeroglu, A.; Bertos, N.; Ouellet, V.; Clemons, M.; Scheffer, G.L.; et al. Abcc5 supports osteoclast formation and promotes breast cancer metastasis to bone. Breast Cancer Res. 2012, 14, R149. [CrossRef]

70. Shao, J.; Zhou, Y.; Xiao, Y. The regulatory roles of notch in osteocyte differentiation via the crosstalk with canonical wnt pathways during the transition of osteoblasts to osteocytes. Bone 2018, 108, 165-178. [CrossRef]

71. Canalis, E.; Adams, D.J.; Boskey, A.; Parker, K.; Kranz, L.; Zanotti, S. Notch signaling in osteocytes differentially regulates cancellous and cortical bone remodeling. J. Biol. Chem. 2013, 288, 25614-25625. [CrossRef] [PubMed]

72. Zhang, Y.; Hassan, M.Q.; Xie, R.L.; Hawse, J.R.; Spelsberg, T.C.; Montecino, M.; Stein, J.L.; Lian, J.B.; van Wijnen, A.J.; Stein, G.S. Co-stimulation of the bone-related runx2 p1 promoter in mesenchymal cells by sp1 and ets transcription factors at polymorphic purine-rich DNA sequences (y-repeats). J. Biol. Chem. 2009, 284, 3125-3135. [CrossRef] [PubMed]

73. Wei, F.; Yang, S.; Guo, Q.; Zhang, X.; Ren, D.; Lv, T.; Xu, X. Microrna-21 regulates osteogenic differentiation of periodontal ligament stem cells by targeting smad5. Sci. Rep. 2017, 7, 16608. [CrossRef]

74. Liu, J.; Li, M.; Liu, X.; Liu, F.; Zhu, J. Mir-27a-3p promotes the malignant phenotypes of osteosarcoma by targeting ten-eleven translocation 1. Int. J. Oncol. 2018, 52, 1295-1304. [CrossRef]

75. Jin, Z.; Zhou, S.; Ye, H.; Jiang, S.; Yu, K.; Ma, Y. The mechanism of sp1/p300 complex promotes proliferation of multiple myeloma cells through regulating iqgap1 transcription. Biomed. Pharmacother. 2019, 119, 109434. [CrossRef]

76. Fulciniti, M.; Amin, S.; Nanjappa, P.; Rodig, S.; Prabhala, R.; Li, C.; Minvielle, S.; Tai, Y.T.; Tassone, P.; Avet-Loiseau, H.; et al. Significant biological role of sp1 transactivation in multiple myeloma. Clin. Cancer Res. 2011, 17, 6500-6509. [CrossRef] 
77. Agarwal, V.; Bell, G.W.; Nam, J.W.; Bartel, D.P. Predicting effective microrna target sites in mammalian mrnas. Elife 2015, 4, e05005. [CrossRef]

78. Sticht, C.; De La Torre, C.; Parveen, A.; Gretz, N. Mirwalk: An online resource for prediction of microrna binding sites. PLoS ONE 2018, 13, e0206239. [CrossRef]

79. Betel, D.; Wilson, M.; Gabow, A.; Marks, D.S.; Sander, C. The microrna.Org resource: Targets and expression. Nucleic Acids Res. 2008, 36, D149-D153. [CrossRef]

80. Pathan, M.; Keerthikumar, S.; Ang, C.S.; Gangoda, L.; Quek, C.Y.; Williamson, N.A.; Mouradov, D.; Sieber, O.M.; Simpson, R.J.; Salim, A.; et al. Funrich: An open access standalone functional enrichment and interaction network analysis tool. Proteomics 2015, 15, 2597-2601. [CrossRef]

(C) 2020 by the authors. Licensee MDPI, Basel, Switzerland. This article is an open access article distributed under the terms and conditions of the Creative Commons Attribution (CC BY) license (http://creativecommons.org/licenses/by/4.0/). 